\title{
Disparities in Utilization of Medical Specialists for Colonoscopy
}

\author{
Michele J. Josey, ${ }^{1-3}$ Cassie L. Odahowski, ${ }^{1-3}$ Whitney E. Zahnd, Mario Schootman,, and Jan M. Eberth ${ }^{1-3, *}$
}

\begin{abstract}
Purpose: Colonoscopy is the preferred screening modality for colorectal cancer (CRC) prevention. The quality of the procedure varies although medical specialists such as gastroenterologists and colorectal surgeons tend to have better outcomes. We aimed to determine whether there are demographic and clinical differences between those who received a colonoscopy from a specialist versus those who received a colonoscopy from a nonspecialist.

Methods: Using the population-based South Carolina Outpatient Ambulatory Surgery Database, we looked retrospectively to obtain patient-level endoscopy records from 2010 to 2014. We used multilevel logistic regression to model whether patients saw a specialist for their colonoscopy. The primary variables were patient race and insurance type, and an interaction by rurality was tested.

Results: Of the 392,285 patients included in the analysis, $81 \%$ saw a specialist for their colonoscopy. County of residence explained $30 \%$ of the variability in the outcome. Non-Hispanic black ( $O R=0.65$; confidence interval [95\% Cl]: 0.64-0.67) and Hispanic patients ( $\mathrm{OR}=0.75 ; 95 \% \mathrm{Cl}$ : 0.67-0.84) were significantly less likely than nonHispanic white patients to see a specialist. Compared with commercial/HMO insurance, all other types were less likely to see a specialist, and even more so for rural patients. The interaction of race by rurality was not significant.

Conclusions: Specialists play a key role in CRC screening and can affect later downstream outcomes. This study has shown that ethnic minorities and adults with public or other insurance, particularly in rural areas, are most likely not to see a specialist. These results are consistent with disparities in CRC incidence, mortality, and survival.
\end{abstract}

Keywords: medical specialty; colonoscopy; screening; physicians; disparities

\section{Introduction}

Colorectal cancer (CRC) is the third most common cancer and the third leading cause of cancer-related death in the United States. ${ }^{1}$ CRC can be both prevented and detected at an earlier more treatable stage with receipt of regular recommended screenings. The overall CRC incidence and mortality have declined by at least $30 \%$ over the past two decades, due in large part to increased screening. ${ }^{2,3}$ However, the racial disparity between Afri- can Americans and white Americans in CRC mortality, and prevalence of adenomas and polyps (which are the precursors to CRC) have persisted. ${ }^{4-7}$ In addition to race, physician-related factors (e.g., medical specialty) and insurance coverage have also been associated with CRC screening and disease outcomes.

Colonoscopy is the preferred cancer prevention modality and was estimated to have contributed to a $77 \%$ and $65 \%$ reduction in CRC incidence and mortality,

\footnotetext{
${ }^{1}$ Department of Epidemiology \& Biostatistics, Arnold School of Public Health, University of South Carolina, Columbia, South Carolina.

${ }^{2}$ Cancer Prevention and Control Program, University of South Carolina, Columbia, South Carolina.

${ }^{3}$ Rural and Minority Health Research Center, University of South Carolina, Columbia, South Carolina.

${ }^{4}$ Department of Clinical Analytics and Insights, Center for Clinical Excellence, SSM Health System, St. Louis, Missouri.

*Address correspondence to: Jan M. Eberth, PhD, University of South Carolina, 915 Greene Street, Columbia, SC 29208, E-mail: jmeberth@mailbox.sc.edu

( ) Jan M. Eberth, et al. 2019; Published by Mary Ann Liebert, Inc. This Open Access article is distributed under the terms of the Creative Commons License (http://creativecommons.org/licenses/by/4.0), which permits unrestricted use, distribution, and reproduction in any medium, provided the original work is properly cited.
} 
respectively. ${ }^{8}$ Colonoscopies are performed by various types of physicians, with varying degrees of quality. Specialty physicians complete additional clinical training in a specific area of medicine beyond their residency. For example, relevant to CRC screening, diagnosis, and treatment, gastroenterologists (GEs) and colorectal surgeons (CRSs) receive fellowship training beyond internal medicine and general surgery residency training, respectively. A colonoscopy is considered an invasive procedure that if not carefully done can have serious adverse effects (e.g., rare bowel perforation) or poor detection of potentially high-risk lesions. ${ }^{9,10}$ GEs are more likely than other specialties to remove adenomas and polyps during a colonoscopy. ${ }^{4,11}$ Research has also shown that having a GE perform the screening colonoscopy is associated with a lower rate of CRC after a negative colonoscopy. ${ }^{12,13}$ Furthermore, CRC patients experience better postoperative outcomes and overall survival when surgery was performed by a CRS than when surgery was performed by a general surgeon. ${ }^{14,15}$ Therefore, considering physician type is important when engaging in research on CRC outcomes.

Although most existing literature shows that specialists have better patient outcomes, specialty services are not equally accessible across population subgroups and geographic regions. For example, Medicare and Medicaid typically pay a lower reimbursement rate than private insurers, motivating physicians to prefer accepting new patients with private insurance. ${ }^{16,17}$ Referral patterns within a health care system or from independent clinics may also dictate the type of physician recommended for screenings such as colonoscopy. ${ }^{18,19}$ Insurance providers, particularly private insurers, typically have lower out-of-pocket costs for in-network providers. This could potentially limit the physician choices of lower income and rural patients because of higher out-of-pocket costs. Therefore, even when specialty physicians are available locally, some patients may experience barriers to care depending on insurance type. ${ }^{20,21}$

In addition to physician characteristics and insurance, urban residence is also associated with better patient outcomes. ${ }^{22}$ National studies have shown greater access to GEs and CRSs in urban counties than in rural areas. ${ }^{23}$ Likewise, GEs are located predominately in urban counties in South Carolina, whereas all the CRSs in the state were located in urban counties. ${ }^{24}$ Studies have shown that rural racial minority patients are often disadvantaged in the quality of cancer care they receive. ${ }^{25,26}$

Racial and socioeconomic disparities in CRC incidence and mortality have been well documented over time. Although CRC outcomes are dependent on physician type, ${ }^{12-15}$ there is a gap in the literature about differences in specialty utilization across population subgroups and geographic regions, particularly for colonoscopy. The purpose of this study was to determine whether there were demographic and clinical differences between those who received a colonoscopy from a specialist versus those who received a colonoscopy from a nonspecialist. We hypothesized that racial/ethnic minorities and patients without private insurance would be more likely to receive colonoscopy from a nonspecialist, and differences in specialist utilization would be further exacerbated by rural residence.

\section{Methods}

\section{Study population}

Data were obtained retrospectively from the South Carolina Outpatient Ambulatory Surgery Database (ASD), a population-based administrative data source with patient-level endoscopy records. We identified colonoscopy procedures using ICD-9, CPT/HCPCS codes (Appendix Table A1) between 2010 and 2014. Each record in the ASD had a unique patient identifier; demographic information including age, sex, race, insurance type, county, and ZIP code; and specialty information on the attending physician. If a patient had more than one colonoscopy during the study period, one record was randomly selected.

The target population for this study were adult patients aged 50-74 years with no personal history of CRC, which aligns with the population recommended for CRC screening by the Multi-Society Task Force on CRC. ${ }^{27}$ Patients were excluded if the ASD record indicated a colonoscopy was urgent/emergency, as the selection of the physician is likely beyond the patient's control.

\section{Outcome}

The outcome for this study was whether patients saw a specialist or nonspecialist for their colonoscopy. A specialist was classified as a GE or CRS, and a nonspecialist physician otherwise. If medical specialty was missing [ $n=78,799$ (4\%) records], we used the 2009 and 2013 South Carolina Medical Board Directory to impute the specialty corresponding to the South Carolina license number. In addition, we used the National Provider Index to further supplement missing license numbers and medical specialty information $[n=485,554$ (26\%) records]. The first physician listed on the colonoscopy record was considered the attending physician and the corresponding medical specialty was used 
when classifying the outcome. If the specialty of the first physician was missing and unable to be imputed, the specialty of the second physician was used, followed by the third specialty if the first two were missing. If the record contained no physician specialty information, it was excluded from the analysis $(n=10,972)$.

\section{Primary independent variables and covariates}

The primary patient variables of interest were race/ethnicity, insurance, and rurality. Race/ethnicity was categorized as non-Hispanic white, non-Hispanic black, Asian, Hispanic, or Other race. However, because the "Other" category was large $[n=63,255(16 \%)]$ and included no subclassifications in the ASD, the results from the "Other" category are not reported. Insurance was categorized as commercial/Health Maintenance Organization (HMO), Medicare, Medicaid, charitable, or Other (i.e., worker's compensation, other government insurance, or not stated). Rurality was categorized using the 2010 Rural-Urban Commuting Area (RUCA) Codes by the United States Department of Agriculture. RUCA codes categorize areas based upon their population density and commuting patterns. ${ }^{28}$ Patients were classified as either urban (1.0, 1.1, 2.0, $2.1,3.0,4.1,5.1,7.1,8.1,10.1)$ or rural $(4.0,5.0,6.0$, 7.0, 7.2, 8.0, 8.2, 9.0, 10.0, 10.2, 10.3).

The covariates considered for inclusion were chosen based on the literature and relationship with CRC: sex, family history of CRC, a personal history of colorectal polyps, having an inflammatory-related disease (Appendix Table A2), distance to the closest specialist, and ZIP code median household income. Distance was calculated as the straight-line distance from the patient ZIP code centroid (i.e., geographic center) to the nearest colonoscopy facility address. Median household income was obtained from the 2007 to 2011 American Community Survey, an ongoing survey performed by the U.S. Census Bureau that provides area-level sociodemographic information and categorized into tertiles. ${ }^{29}$ Patients were excluded if they had any missing covariates $(n=10,972)$.

\section{Statistical analysis}

We performed chi-square analysis and $t$-tests to compare demographic and clinical characteristics of patients who had a colonoscopy by a specialist versus patients who had a colonoscopy by a nonspecialist. We used multilevel multivariable logistic regression to model the odds of seeing a specialist. Because patients are nested within regions, we included patient county as a random effect. First, we ran an empty model that only included the random effect and calculated the intraclass correlation (ICC) to determine whether type of physician (specialty or not) varied across counties. ${ }^{30}$ Model 1 presents the relationship between physician type and each of the independent variables separately. Model 2 adjusts for the covariates and Model 3 includes an interaction term of rurality status between race and insurance. All models included the county-level random intercept. Interaction terms were tested to determine whether racial/ethnic or insurance differences were exacerbated by rurality. Data management and analyses were conducted in $\mathrm{R}$ version 3.5.2.

\section{Results}

There were 392,285 patients included in the analysis and $81 \%$ saw a specialist for their colonoscopy. Although most patients saw a specialist, differences were present by race/ethnicity and insurance status. Table 1 shows that Asian patients had the highest proportion of colonoscopy performed by a specialist (85\%), followed by white (81\%), Hispanic (79\%), and black (73\%) patients. More commercial/HMO and charitable insurance holders $(83 \%)$ saw a specialist than Medicare (80\%), Medicaid $(73 \%)$, and self-payers (73\%). Urban patients were also more likely to see a specialist (82\%) than rural patients (75\%). Those having a history of a colorectalrelated condition were more likely to see a specialist than patients with no history $(p<0.001)$. There was also a positive association between ZIP code median household income and seeing a specialist $(p<0.001)$; $89 \%$ of patients from the highest median income tertile saw a specialist versus $72 \%$ from the lowest median income tertile. Patients who had a colonoscopy in an ambulatory surgery center were significantly more likely to see a specialist than those who went to a hospital $(91.0 \%$ vs. $68.4 \%, p<0.001)$.

The empty model with the county-level random effect showed that $32 \%$ of the variability was explained by the patients' county of residence $(\mathrm{ICC}=0.321)$. Model 1 showed that non-Hispanic black and Hispanic patients had lower odds of seeing a specialist than non-Hispanic whites, and Asian patients had equivalent odds. Those with Medicare, Medicaid, or self-pay were significantly less likely to see a specialist than those with commercial/HMO insurance, whereas those with other insurance were more likely. Rural patients also had lower odds of seeing a specialist than their urban counterparts.

In the adjusted Model 2, non-Hispanic black (OR= 0.65 ; confidence interval $[95 \% \mathrm{CI}]: 0.64-0.67)$ and 
Table 1. Characteristics of Study Participants That Received a Colonoscopy from 2010 to 2014, $n=392,285$

\begin{tabular}{|c|c|c|c|}
\hline Characteristic & $\begin{array}{c}\text { Total } \\
\text { population, } \\
N(\%)\end{array}$ & $\begin{array}{c}\text { Saw a } \\
\text { specialist, } \\
n(\%)\end{array}$ & $p$ \\
\hline & $392,285(100)$ & $318,369(81.2)$ & \\
\hline \multicolumn{4}{|l|}{ Race } \\
\hline Asian & $1655(0.4)$ & $1412(85.3)$ & $<0.001$ \\
\hline Non-Hispanic black & $73,942(18.8)$ & $53,877(72.9)$ & \\
\hline Non-Hispanic white & $251,468(64.1)$ & $203,972(81.1)$ & \\
\hline Hispanic & $1965(0.5)$ & $1556(79.2)$ & \\
\hline Other & $63,255(16.1)$ & $57,552(91.0)$ & \\
\hline \multicolumn{4}{|l|}{ Insurance } \\
\hline Commercial/HMO & $216,716(55.2)$ & $178,701(82.5)$ & $<0.001$ \\
\hline Medicare & $133,140(33.9)$ & $106,128(79.7)$ & \\
\hline Medicaid & $10,814(2.8)$ & $7842(72.5)$ & \\
\hline Self-pay & $8144(2.8)$ & $5648(73.0)$ & \\
\hline Charitable & $5835(1.5)$ & $1818(82.6)$ & \\
\hline Other & $17,636(4.5)$ & $14,932(84.7)$ & \\
\hline \multicolumn{4}{|l|}{ Rurality } \\
\hline Urban & $365,649(93.2)$ & $298,466(81.6)$ & $<0.001$ \\
\hline Rural & $26,636(6.8)$ & $19,903(74.7)$ & \\
\hline \multicolumn{4}{|l|}{ Sex } \\
\hline Male & $174,102(44.4)$ & $139,521(80.1)$ & $<0.001$ \\
\hline Female & $218,183(55.6)$ & $178,848(82.0)$ & \\
\hline \multicolumn{4}{|l|}{ Age } \\
\hline $50-54$ & $100,755(25.7)$ & $81,269(80.7)$ & $<0.001$ \\
\hline $55-59$ & $79,680(20.3)$ & $64,114(80.5)$ & \\
\hline $60-65$ & $81,895(20.9)$ & $67,061(81.9)$ & \\
\hline $65-69$ & $77,389(19.7)$ & $62,861(81.2)$ & \\
\hline $70-74$ & $52,566(13.4)$ & $43,064(81.9)$ & \\
\hline \multicolumn{4}{|c|}{ Colorectal-related conditions } \\
\hline Family history of CRC & $49,414(12.6)$ & $41,116(83.2)$ & $<0.001$ \\
\hline Colonic polyps & $74,068(18.9)$ & $65,379(88.3)$ & $<0.001$ \\
\hline Inflammatory disease & $7382(1.9)$ & $6721(91)$ & $<0.001$ \\
\hline $\begin{array}{l}\text { Median ZIP code } \\
\text { income }(\$)^{\mathrm{a}}\end{array}$ & $47,238(13,197)$ & $48,260(13,181)$ & $<0.001$ \\
\hline$\leq \$ 40,984$ & 130,218 & $94,022(72.2)$ & \\
\hline$\$ 52,500-\$ 40,985$ & 137,282 & $113,752(82.6)$ & \\
\hline$>\$ 52,500$ & 124,785 & 110,595 & \\
\hline $\begin{array}{l}\text { Distance to closest } \\
\text { specialist (miles) }^{\text {a }}\end{array}$ & $7.24(5.24)$ & $7.00(5.09)$ & $<0.001$ \\
\hline \multicolumn{4}{|l|}{ Place of procedure } \\
\hline $\begin{array}{l}\text { Ambulatory surgery } \\
\text { center }\end{array}$ & $221,522(56.5)$ & $201,745(91.1)$ & $<0.001$ \\
\hline Hospital & $170,763(43.5)$ & $116,624(68.3)$ & \\
\hline
\end{tabular}

Specialists were defined as gastroenterologist and colorectal surgeons. "Saw a specialist" column was calculated as the number of patients who saw a specialist divided by the total population of each demographic group. $p$-Values correspond to the "Saw a specialist" column.

${ }^{a}$ Distance values are given as the mean (standard deviation) and was calculated as the straight-line distance from the patient ZIP code centroid to the closest physician specialist performing colonoscopy.

HMO, Health Maintenance Organization; CRC, colorectal cancer.

Hispanic $(\mathrm{OR}=0.75 ; 95 \%$ CI: 0.67-0.84) patients remained significantly less likely to see a specialist than non-Hispanic white patients. Compared with patients with commercial/HMO insurance, patients who were self-paying $(\mathrm{OR}=0.61 ; 95 \% \mathrm{CI}$ : $0.58-0.64)$, on Medicare $(\mathrm{OR}=0.87,95 \% \mathrm{CI}$ : $0.85-0.90)$, Medicaid ( $\mathrm{OR}=0.74 ; 95 \%$ CI: 0.71-0.78), charitable assistance $(\mathrm{OR}=0.82$; 95\% CI: $0.76-0.88)$, or other insurance plans $(\mathrm{OR}=0.82$; $95 \% \mathrm{CI}: 0.78-0.86)$ were significantly less likely to see a specialist. The association between rural residence and seeing a specialist was slightly attenuated in the adjusted model $(\mathrm{OR}=0.93$; 95\% CI: $(0.89-0.99)$. The odds of seeing a specialist increased with age, wherein patients 70 years or older had $\sim 11 \%$ higher odds than patients aged 50-55 years. Patients with a history of colorectal-related conditions were significantly more likely to see a specialist (Table 2).

The interaction of rurality with race/ethnicity was not statistically significant and not included in the final model, whereas the interaction with insurance revealed further differences. Rural patients who selfpaid or had other insurance were not significantly different from urban patients who had commercial/HMO insurance. For the remaining insurance types, rural patients were similar or less likely to see a specialist than urban patients (Fig. 1). The ICC for the choice of the

Table 2. Odds Ratio (95\% Confidence Interval) of Seeing a Specialist for South Carolina Residents for Colonoscopy, 2010-2014, $n=392,285$

\begin{tabular}{|c|c|c|}
\hline & Model 1 & Model 2 \\
\hline \multicolumn{3}{|l|}{ Race/ethnicity } \\
\hline White & 1.00 & 1.00 \\
\hline Black & $0.60(0.59-0.62)^{*}$ & $0.65(0.64-0.67)^{*}$ \\
\hline Asian & $1.01(0.90-1.14)$ & $1.06(0.92-1.23)$ \\
\hline Hispanic & $0.67(0.60-0.74)^{*}$ & $0.75(0.67-0.84)^{*}$ \\
\hline \multicolumn{3}{|l|}{ Insurance } \\
\hline Commercial/HMO & 1.00 & 1.00 \\
\hline Self-pay & $0.57(0.54-0.61)^{*}$ & $0.61(0.58-0.64)^{*}$ \\
\hline Medicare & $0.91(0.89-0.93)^{*}$ & $0.87(0.85-0.90)^{*}$ \\
\hline Medicaid & $0.63(0.60-0.66)^{*}$ & $0.74(0.71-0.78)^{*}$ \\
\hline Charitable & $0.68(0.63-0.73)^{*}$ & $0.82(0.76-0.88)^{*}$ \\
\hline Other & $0.88(0.84-0.92)^{*}$ & $0.82(0.78-0.86)^{*}$ \\
\hline \multicolumn{3}{|l|}{ Rurality } \\
\hline Urban & 1.00 & 1.00 \\
\hline Rural & $0.91(0.87-0.96)^{* *}$ & $0.93(0.89-0.99)^{*-3}$ \\
\hline \multicolumn{3}{|l|}{ Age } \\
\hline $50-54$ & & 1.00 \\
\hline $55-59$ & & $0.99(0.97-1.02)$ \\
\hline $60-64$ & & $1.06(1.03-1.09)^{*}$ \\
\hline $65-69$ & & $1.07(1.04-1.10)^{*}$ \\
\hline $70-75$ & & $1.11(1.07-1.15)^{*}$ \\
\hline \multicolumn{3}{|l|}{ Sex } \\
\hline Female & & 1.00 \\
\hline Male & & $0.82(0.81-0.83)^{*}$ \\
\hline \multicolumn{3}{|l|}{ Colorectal-related conditions } \\
\hline Family history of CRC & & $1.20(1.17-1.23)^{*}$ \\
\hline History of colorectal polyps & & $1.82(1.77-1.87)^{*}$ \\
\hline Inflammatory disease & & $2.76(2.54-3.00)^{*}$ \\
\hline \multicolumn{3}{|l|}{ Median ZIP code income } \\
\hline$>\$ 52,500$ & & 1.00 \\
\hline$\$ 52,500-\$ 40,985$ & & $0.89(0.87-0.92)^{*}$ \\
\hline$\leq \$ 40,984$ & & $0.80(0.77-0.82)^{*}$ \\
\hline
\end{tabular}

${ }^{*} p<0.0001,{ }^{* *} p<0.01,{ }^{* * *} p<0.05$

The random effect was included as a random intercept for each county. Model 1 shows the relationship between physician type and each of the independent variables separately. Model 2 adjusts for the covariates. The intraclass correlation for the random effect in Models 2 and 3 was 0.296. 


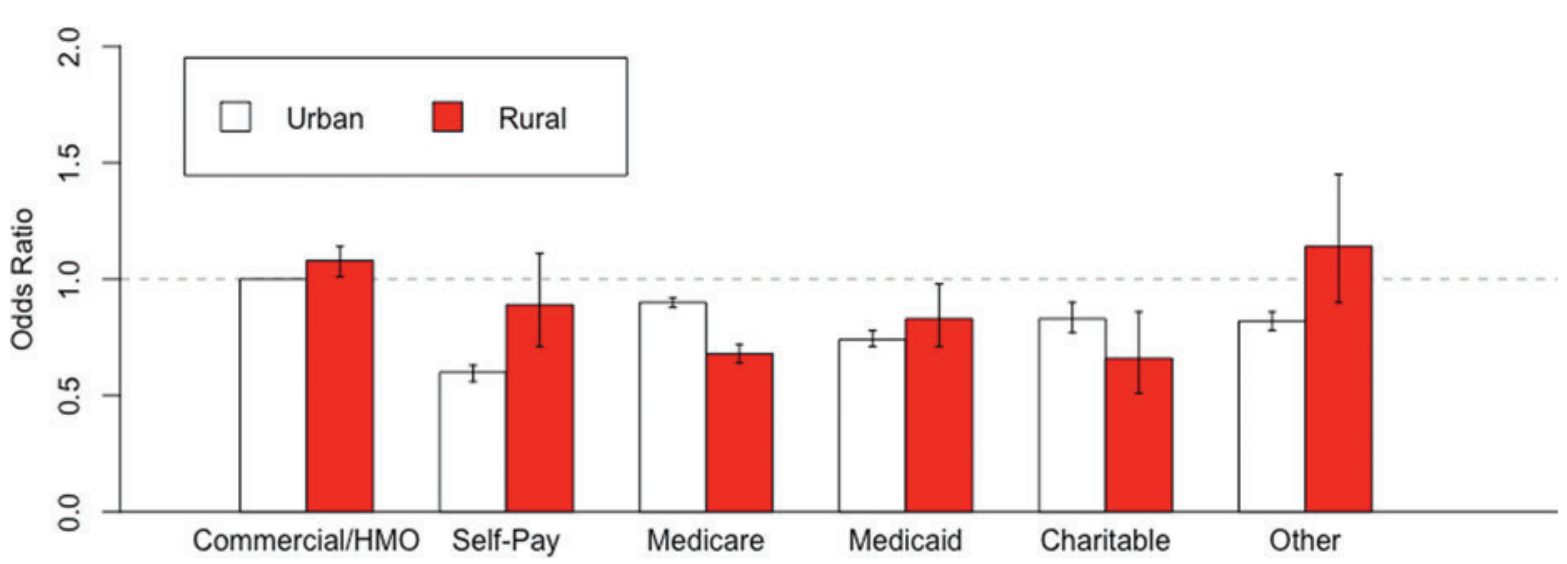

FIG. 1. Adjusted odds ratio of seeing a specialist for the interaction of rurality with insurance.

type of physician across counties was reduced only slightly when including all covariates $(\mathrm{ICC}=0.296)$.

\section{Discussion}

We determined which sociodemographic and clinical characteristics were associated with utilizing a specialist for a colonoscopy procedure. Non-Hispanic black and Hispanic patients were less likely than nonHispanic white patients to see a specialist, whereas Asian patients' utilization of specialists was no different than non-Hispanic white patients. Consistent with nationwide trends showing a declining availability of physician specialists in rural areas, ${ }^{23,31}$ rural patients were less likely to see a specialist for colonoscopy. Our hypothesis that rurality exacerbated disparities was confirmed for insurance status, but not for racial/ethnicity.

We found that non-Hispanic black patients had lower odds of seeing a specialist. In a study of male cancer survivors, Palmer et al. found that African American male cancer survivors were almost twice as likely not to have seen a specialist in the past 12 months than white survivors. ${ }^{32}$ Although black adults are slightly less likely to receive any CRC screening, an estimated one out of three men reported not receiving a screening recommendation from their physician. ${ }^{33,34}$ This lack of communication could transfer to disseminating the importance of physician selection for colonoscopy. Laiyemo et al. found no racial differences in pathological findings of diagnostic colonoscopies in the prostate, lung, colorecal, and ovarian trial, suggesting that observed disparities in CRC outcomes (e.g., lower adherence to follow-up testing and sur- vival) may be due to access and health care utilization differences as opposed to biology. ${ }^{35}$ Similarly, a study on the Colorectal Cancer Prevention Network, a (free) screening program for low-income uninsured adults, found no racial differences in adenoma and polyp detection. ${ }^{36}$ All of the physicians who participated in the program were GEs. Our findings coupled with previous research suggest that racial disparities in CRC outcomes may be due in large part to access and utilization of high-quality screening and treatment. Interestingly, the odds that rural ethnic minorities saw a specialist were no different than their urban counterparts, even though specialty physicians are more prevalent in urban areas. Future studies should investigate whether this phenomenon is due to preference, lack of communication, or a byproduct of insurance coverage, as well as extend these findings to examine the effects of the receipt of colonoscopy from a specialist on long-term CRC outcomes.

Overall, patients who self-paid or had public insurance were less likely to receive a colonoscopy from a specialist. Apart from those with "Other" insurance, patients with insurance other than commercial/HMO were more likely to receive their colonoscopy in an outpatient hospital setting (data not shown). In South Carolina, 63\% of GEs work primarily in ambulatory surgery centers and nonspecialists comprise a larger proportion of outpatient hospital-based endoscopy services. ${ }^{24}$ Our finding that Medicaid patients used a nonspecialist more than patients with commercial/HMO insurance may relate to the costs of performing the procedure. Unlike Medicare, coverage for Medicaid is not federally guaranteed for individuals not experiencing CRC-related symptoms. ${ }^{37}$ 
Finally, medical specialists who perform colonoscopy tend to perform a higher volume of procedures, ${ }^{24,38}$ which may be a major driving force behind better quality and colorectal outcomes. ${ }^{39,40}$ Some studies have found that despite volume or experience, GEs have superior quality outcomes. ${ }^{11,41}$ Other studies have shown that primary care physicians have the ability to have comparable metrics with colonoscopy specialists with the appropriate training and support. ${ }^{42-44}$ Although it may be difficult to disentangle the effect of medical training from procedure volume, accounting for the medical specialty of the physician or their procedure volume remains important in studies of CRC outcomes.

\section{Limitations and strengths}

There are a few limitations to note. The data are an administrative-based resource, and our results are dependent on the accuracy of the data. Also, the available database did not have individual-level socioeconomic variables. A ZIP code-level variable was included instead, and it was shown to be a confounder and improved the model fit, a method that previous cancer studies have done. ${ }^{45,46}$ Despite these limitations, this study is innovative because we used a population-based data source (i.e., generalizable across the entire state) of adults who received a colonoscopy and had the power to detect subgroup differences across race/ethnicity, insurance status, and patient county of residence.

\section{Conclusion}

This study illustrated how CRC disparities go beyond outcomes such as incidence and mortality, but also may exist in the provision of CRC testing. Specialists play a key role in CRC screening and can affect later downstream outcomes including improved survival. ${ }^{12-15}$ Our results point toward the need for targeted efforts to improve access and utilization of physician specialists for colonoscopy among racial/ethnic minorities and rural residents through expanding specialty practices into rural areas or improving rural access to urban specialists (e.g., mobile screening units and rotating practice sites). However, even in urban environments with greater availability of specialty physicians, racial/ethnic minorities, and those on public insurance may still be disadvantaged in accessing specialty care. Culturally tailored messaging for patients regarding how to access physician specialists (and why they are important) and self-advocacy in health care decisions may help to bridge the gap. In addition, system and policy changes to ensure equal access to physician specialists across insurance types may further mitigate observed differences.

\section{Acknowledgment}

We would like to thank Erica Sercy for her efforts on this topic during the early stages.

\section{Authors' Contributions}

M.J.J. and J.M.E. conceptualized the study. M.J.J. wrote the first draft of the article and performed statistical analysis. C.L.O., W.E.Z., M.S., and J.M.E. helped interpret the findings, critically edited multiple article drafts, and approved the final article.

\section{Author Disclosure Statement}

No competing financial interests exist.

\section{Funding Information}

This study was supported by the American Cancer Society (J.M.E.; MRSG-15-148-01-CPHPS) and the National Institute of General Medical Sciences (M.J.J.; T32GM081740).

\section{References}

1. Siegel RL, Miller KD, Jemal A. Cancer statistics, 2018. CA Cancer J Clin. 2018;68:7-30.

2. Levin TR, Corley DA, Jensen CD, et al. Effects of organized colorectal cancer screening on cancer incidence and mortality in a large communitybased population. Gastroenterology. 2018;155:1383-1391.e5.

3. Shaukat A, Mongin SJ, Geisser MS, et al. Long-term mortality after screening for colorectal cancer. N Engl J Med. 2013;369:1106-1114.

4. Parikh MP, Muthukuru S, Jobanputra $Y$, et al. Sessile serrated adenomas are more prevalent in Caucasians, and gastroenterologists are better than nongastroenterologists at their detection. Gastroenterol Res Pract. 2017;2017. DOI: 10.1155/2017/6710931.

5. American Cancer Society. Colorectal Cancer Facts \& Figures 2017-2019. 2017. DOI: http://dx.doi.org/10.1016/S0140-6736(13)61649-9

6. Corley DA, Jensen CD, Marks AR, et al. Variation of adenoma prevalence by age, sex, race, and colon location in a large population: implications for screening and quality programs. Clin Gastroenterol Hepatol. 2013;11: $172-180$.

7. Lieberman DA, Williams JL, Holub JL, et al. Race, ethnicity, and sex affect risk for polyps greater than $9 \mathrm{~mm}$ in average-risk individuals. Gastroenterology. 2014;147:351-358.

8. Dinh T, Ladabaum U, Alperin P, et al. Health benefits and costeffectiveness of a hybrid screening strategy for colorectal cancer. Clin Gastroenterol Hepatol. 2013;11:1158-1166.

9. Castro G, Azrak MF, Seeff LC, et al. Outpatient colonoscopy complications in the CDC's Colorectal Cancer Screening Demonstration Program: a prospective analysis. Cancer. 2013;119(Suppl. 15):2849-2854.

10. Zwink N, Holleczek B, Stegmaier C, et al. Complication rates in colonoscopy screening for cancer-a prospective cohort study of complications arising during the procedure and in the ensuing four weeks. Dtsch Arztebl Int. 2017;114:321-327.

11. Pace $D$, Borgaonkar $M$, Lougheed $M$, et al. Effect of colonoscopy volume on quality indicators. Can J Gastroenterol Hepatol. 2016;2016:2580894.

12. Rabeneck L, Paszat LF, Saskin R. Endoscopist specialty is associated with incident colorectal cancer after a negative colonoscopy. Clin Gastroenterol Hepatol. 2010;8:275-279.

13. Jiang $M$, Sewitch MJ, Barkun AN, et al. Endoscopist specialty is associated with colonoscopy quality. BMC Gastroenterol. 2013;13:78.

14. Biondo $S$, Kreisler $E$, Millan $M$, et al. Impact of surgical specialization on emergency colorectal surgery outcomes. Arch Surg. 2010;145: 79-86.

15. Etzioni DA, Young-Fadok TM, Cima RR, et al. Patient survival after surgical treatment of rectal cancer: impact of surgeon and hospital characteristics. Cancer. 2014;120:2472-2481. 
16. Decker SL. In 2011 nearly one-third of physicians said they would not accept new Medicaid patients, but rising fees may help. Health Aff. 2012; 31:1673-1679.

17. Cunningham PJ, O'Malley AS. Do reimbursement delays discourage Medicaid participation by physicians? Health Aff. 2009;28:17-28

18. Carlin CS, Feldman R, Dowd B. The impact of hospital acquisition of physician practices on referral patterns. Health Econ. 2016;25:439-454.

19. Cook NL, Hicks LS, O'Malley AJ, et al. Access to specialty care and medical services in community health centers. Health Aff. 2007;26:1459-1468.

20. McDavid K, Tucker TC, Sloggett A, et al. Cancer survival in Kentucky and health insurance coverage. Arch Intern Med. 2003;163:2135-2144.

21. Roetzheim RG, Pal N, Gonzalez EC, et al. Effects of health insurance and race on colorectal cancer treatments and outcomes. Am J Public Health. 2000;90:1746-1754

22. Al-Sahaf $M$, Lim $E$. The association between surgical volume, survival and quality of care. J Thorac Dis. 2015;7(Suppl. 2):S152-S155.

23. Aboagye JK, Kaiser HE, Hayanga AJ. Rural-urban differences in access to specialist providers of colorectal cancer care in the United States. JAMA Surg. 2014;149:537.

24. Eberth JM, Josey MJ, Mobley LR, et al. Who performs colonoscopy? Workforce trends over space and time. J Rural Health. 2017;34:138-147.

25. Le $\mathrm{H}$, Ziogas A, Lipkin SM, et al. Effects of socioeconomic status and treatment disparities in colorectal cancer survival. Cancer Epidemiol Biomarkers Prev. 2008;17:1950-1962.

26. Gruber K, Soliman AS, Schmid K, et al. Disparities in the utilization of laparoscopic surgery for colon cancer in rural Nebraska: a call for placement and training of rural general surgeons. J Rural Health. 2015;31:392-400.

27. Rex DK, Boland CR, Dominitz JA, et al. Colorectal cancer screening: recommendations for physicians and patients from the U.S. Multi-Society Task Force on Colorectal Cancer. Am J Gastroenterol. 2017;112:1016-1030.

28. United States Department of Agriculture. 2010 Rural-Urban Commuting Area (RUCA) Codes. 2016. Available at www.ers.usda.gov/data-products/ rural-urban-commuting-area-codes/documentation Accessed November 14, 2018.

29. US Census Bureau. American Community Survey. 2011. Available at www.census.gov/programs-surveys/acs/news/data-releases.2011.html Accessed January 28, 2019.

30. Wu S, Crespi CM, Wong WK. Comparison of methods for estimating the intraclass correlation coefficient for binary responses in cancer prevention cluster randomized trials. Contemp Clin Trials. 2012;33:869-880.

31. Charlton M, Schlichting J, Chioreso $C$, et al. Challenges of rural cancer care in the United States. Oncology. 2015;29:633-640.

32. Palmer NRA, Geiger AM, Felder TM, et al. Racial/ethnic disparities in health care receipt among male cancer survivors. Am J Public Health. 2013;103 1306-1313.

33. Coleman Wallace DA, Baltrus PT, Wallace TC, et al. Black White disparities in receiving a physician recommendation for colorectal cancer screening and reasons for not undergoing screening. J Health Care Poor Underserved. 2013;24:1115-1124.

34. May FP, Almario CV, Ponce $\mathrm{N}$, et al. Racial minorities are more likely than whites to report lack of provider recommendation for colon cancer screening. Am J Gastroenterol. 2015;110:1388-1394.
35. Laiyemo AO, Doubeni C, Pinsky PF, et al. Race and colorectal cancer disparities: health-care utilization vs different cancer susceptibilities. J Natl Cancer Inst. 2010;102:538-546.

36. Eberth JM, Thibault A, Caldwell R, et al. A statewide program providing colorectal cancer screening to the uninsured of South Carolina. Cancer. 2018;124:1912-1920.

37. American Cancer Society. Insurance coverage for colorectal cancer screening. 2018. Available at www.cancer.org/cancer/colon-rectalcancer/detection-diagnosis-staging/screening-coveragelaws.html\#written_by Accessed February 15, 2018.

38. Hall GM, Shanmugan S, Bleier JIS, et al. Colorectal specialization and survival in colorectal cancer. Color Dis. 2016;18:051-060.

39. Zwink N, Stock C, Birkner B, et al. Screening colonoscopy volume and detection of colorectal neoplasms: a state-wide study from Bavaria, Germany. Eur J Cancer Prev. 2017;26:181-188.

40. Qayed E, Vora R, Levy S, et al. Colonoscopy procedural volume increases adenoma and polyp detection rates in gastroenterology trainees. World J Gastrointest Endosc. 2017;9:540-551.

41. Leyden JE, Doherty GA, Hanley A, et al. Quality of colonoscopy performance among gastroenterology and surgical trainees: a need for common training standards for all trainees? Endoscopy. 2011;43:935-940.

42. Kolber MR, Wong CKW, Fedorak RN, et al. Prospective study of the quality of colonoscopies performed by primary care physicians: the Alberta Primary Care Endoscopy (APC-Endo) Study. PLoS One. 2013;8:2-9.

43. Massl R, van Putten PG, Steyerberg EW, et al. Comparing quality, safety, and costs of colonoscopies performed by nurse vs physician trainees. Clin Gastroenterol Hepatol. 2014;12:470-477.

44. Xirasagar S, Hurley TG, Sros L, et al. Quality and safety of screening colonoscopies performed by primary care physicians with standby specialist support. Med Care. 2010;48:703-709.

45. Hussain T, Chang HY, Luu NP, et al. The value of continuity between primary care and surgical care in colon cancer. PLoS One. 2016;11:1-15.

46. Lin Y, Wimberly MC. Geographic variations of colorectal and breast cancer late-stage diagnosis and the effects of neighborhood-level factors. J Rural Health. 2017;33:146-157.

Cite this article as: Josey MJ, Odahowski $\mathrm{CL}$, Zahnd WE, Schootman M, Eberth JM (2019) Disparities in utilization of medical specialists for colonoscopy, Health Equity 3:1, 464-471, DOI: 10.1089/heq.2019.0052.

$\begin{aligned} & \text { Abbreviations Used } \\ & \mathrm{ASD}= \text { Ambulatory Surgery Database } \\ & \mathrm{Cl}=\text { confidence interval } \\ & \mathrm{CRC}=\text { colorectal cancer } \\ & \mathrm{CRSs}=\text { colorectal surgeons } \\ & \mathrm{GEs}=\text { gastroenterologists } \\ & \mathrm{ICC}=\text { intraclass correlation } \\ & \mathrm{RUCA}=\text { Rural-Urban Commuting Area }\end{aligned}$

\section{Publish in Health Equity}

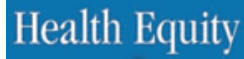

- Immediate, unrestricted online access

- Rigorous peer review

- Compliance with open access mandates

- Authors retain copyright

- Highly indexed

- Targeted email marketing

liebertpub.com/heq 


\section{Appendix}

Appendix Table A1. CPT, HCPCS, and ICD-9 Codes Used to Identify Colonoscopy in Outpatient Data Set

\begin{tabular}{|c|c|}
\hline Code & Description \\
\hline G0105 & $\begin{array}{l}\text { Colorectal cancer screening; colonoscopy on individual } \\
\text { at high risk }\end{array}$ \\
\hline G0121 & $\begin{array}{l}\text { Colorectal cancer screening; colonoscopy on individual } \\
\text { not meeting the criteria for high risk }\end{array}$ \\
\hline 44388 & Colonoscopy through stoma \\
\hline 44389 & Colonoscopy through stoma with biopsy \\
\hline 44390 & Colonoscopy through stoma with foreign body removal \\
\hline 44391 & Colonoscopy through stoma with control of bleeding \\
\hline 44392 & Colonoscopy through stoma with hot biopsy \\
\hline 44393 & $\begin{array}{l}\text { Colonoscopy through stoma with ablation of tumor(s), } \\
\text { polyp(s), or other lesion(s) not amenable } \\
\text { to removal by hot biopsy forceps, bipolar cautery, or snare } \\
\text { technique }\end{array}$ \\
\hline 44394 & Colonoscopy through stoma with snare \\
\hline 44397 & $\begin{array}{l}\text { Colonoscopy through stoma with transendoscopic stent } \\
\text { placement }\end{array}$ \\
\hline 45355 & Transabdominal colonoscopy via colotomy \\
\hline 45378 & Colonoscopy \\
\hline 45379 & Colonoscopy with foreign body removal \\
\hline 45380 & Colonoscopy with biopsy \\
\hline 45381 & Colonoscopy with submucosal injection \\
\hline 45382 & Colonoscopy with control of bleeding \\
\hline 45383 & $\begin{array}{l}\text { Colonoscopy with ablation of tumor(s), polyp(s), or other } \\
\text { lesion(s) not amenable to removal by hot biopsy, } \\
\text { forceps, bipolar cautery, or snare technique }\end{array}$ \\
\hline 45384 & Colonoscopy with hot biopsy \\
\hline 45385 & Colonoscopy with snare \\
\hline 45386 & Colonoscopy with dilation \\
\hline 45387 & Colonoscopy with transendoscopic stent placement \\
\hline 45391 & Colonoscopy with endoscopic ultrasound \\
\hline 45392 & Colonoscopy with endoscopic ultrasound with FNA \\
\hline 45.21 & Transabdominal endoscopy of large intestine \\
\hline 45.22 & Endoscopy of large intestine through artificial stoma \\
\hline 45.23 & Colonoscopy \\
\hline 45.25 & Endoscopic biopsy of large intestine \\
\hline 45.41 & Excision of lesion or tissue of large intestine \\
\hline 45.42 & Endoscopic polypectomy of large intestine \\
\hline 45.43 & $\begin{array}{l}\text { Endoscopic destruction of other lesion or tissue } \\
\text { of large intestine }\end{array}$ \\
\hline 48.24 & Endoscopic biopsy of rectum \\
\hline 48.36 & Endoscopic polypectomy of rectum \\
\hline
\end{tabular}

Appendix Table A2. CPT, HCPCS, and ICD-9 Codes Used to Identify History of Colorectal-Related Diseases in Outpatient Data Set

\begin{tabular}{ll}
\hline Code & \multicolumn{1}{c}{ Description } \\
\hline $\begin{array}{l}\text { Personal history } \\
\text { V10.05 }\end{array}$ & Personal history of malignant neoplasm of large intestine \\
V10.06 & Personal history of malignant neoplasm of rectum, \\
& rectosigmoid junction, and anus \\
V12.72 & Personal history of colonic polyps \\
Family history & \\
V16.0 & Family history of malignant neoplasm of gastrointestinal \\
& tract \\
Inflammatory-related diseases \\
555.0 & Regional enteritis of small intestine \\
555.1 & Regional enteritis of large intestine \\
555.2 & Regional enteritis of small intestine with large intestine \\
555.9 & Regional enteritis of unspecified site \\
556.0 & Ulcerative (chronic) enterocolitis \\
556.1 & Ulcerative (chronic) ileocolitis \\
556.2 & Ulcerative (chronic) proctitis \\
556.3 & Ulcerative (chronic) proctosigmoiditis \\
556.4 & Pseudopolyposis of colon \\
556.5 & Left-sided ulcerative (chronic) colitis \\
556.6 & Universal ulcerative (chronic) colitis \\
556.8 & Other ulcerative colitis \\
556.9 & Ulcerative colitis, unspecified \\
564.1 & Irritable bowel disease/syndrome \\
\end{tabular}

